\title{
A modified surgical approach for hard and soft tissue reconstruction of severe periimplantitis defects: laser-assisted periimplant defect regeneration (LAPIDER)
}

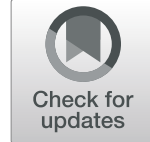

Robert Noelken ${ }^{1,2^{*}}$ and Bilal Al-Nawas ${ }^{2}$

\begin{abstract}
Background: The main problem in periimplantitis is often the combination of severe periimplant bone loss with a contaminated implant surface and an insufficient soft tissue situation. Classic surgical concepts with crestal access to the bony defect and debridement of the surface most often lead to partial defect regeneration and a soft tissue recession. An incision directly above the pathologic bony lesion is contrary to general surgical treatment rules.

Aim: To overcome this problem, a new surgical concept was developed which allows to clean the implant surface, reconstruct the bony defect, and improve soft tissue height and thickness without cutting the papilla complex. This publication presents the innovative regenerative treatment approach for severe periimplantitis defects.

Material and methods: After diagnosis and non-surgical pre-treatment of a severe periimplantitis lesion, the following treatment protocol was applied: horizontal mucosal incision $5 \mathrm{~mm}$ apical to marginal mucosa, supraperiosteal preparation in apical direction, cutting through periosteum at the level of the implant apex, subperiosteal coronal flap elevation, exploration and cleaning of the periimplant defect, thorough debridement of the implant surface with the Er:YAG laser, subperiosteal grafting with connective tissue, grafting of the bony defect with autogenous bone chips from the mandibular ramus, and bilayered suturing of periosteum and mucosa. Implant survival, marginal bone levels, periimplant probing depths, recession, and facial mucosa thickness (PIROP ultrasonic measurement) were evaluated in a pilot case at 1-year follow-up examination.

Results: Inter-proximal, oral, and buccal marginal bone levels increased significantly to the level of the implant shoulder from pre-operative to 1-year follow-up examination. No signs of suppuration or periimplant infection were present. Probing depths and recession decreased significantly, while the facial mucosa thickness improved from pre-operative to final examination.

(Continued on next page)
\end{abstract}

\footnotetext{
* Correspondence: rnoelken@me.com

${ }^{1}$ Private Practice for Oral Surgery, Paradiesplatz 7-13, 88131 Lindau/Lake

Constance, Germany

²Department of Oral and Maxillofacial Surgery, University Medical Center,

Johannes Gutenberg University of Mainz, Mainz, Germany
}

\section{Springer Open}

(c) The Author(s). 2020 Open Access This article is licensed under a Creative Commons Attribution 4.0 International License, which permits use, sharing, adaptation, distribution and reproduction in any medium or format, as long as you give appropriate credit to the original author(s) and the source, provide a link to the Creative Commons licence, and indicate if changes were made. The images or other third party material in this article are included in the article's Creative Commons licence, unless indicated otherwise in a credit line to the material. If material is not included in the article's Creative Commons licence and your intended use is not permitted by statutory regulation or exceeds the permitted use, you will need to obtain permission directly from the copyright holder. To view a copy of this licence, visit http://creativecommons.org/licenses/by/4.0/. 
(Continued from previous page)

Conclusions: Marginal bone levels and soft tissue improvement suggest feasibility for the regeneration of severe periimplant hard and soft tissue deficiencies by this new treatment approach. With the use of this concept, the simultaneous implant surface cleansing and improvement of hard and soft tissue seem to be possible and unfavorable postoperative exposition of titanium surface might be prevented. Comparative studies are planned to quantify the effects of this new surgical protocol.

Keywords: Periimplantitis, Laser, Bone grafting, Soft tissue grafting, Soft tissue Thickness, Bone regeneration, Recession, CB-CT, Attached mucosa, Ultrasonic measurement,

\section{Introduction}

Soft tissue health around dental implants, the prevention and treatment of periimplantitis, and the maintenance of periimplant esthetics have become an important topic in implant dentistry. The main problem in periimplantitis is often the combination of severe perimplant bone loss with a contaminated implant surface and an insufficient soft tissue situation.

Surgical regenerative treatment is a predictable option in managing periimplantitis and improving clinical parameters of periimplant tissues, even there wasn't found an advantage of membrane use for bone graft coverage or the submergence of the implant site following peri-implant defect treatment on periimplant regeneration [1].

Classic surgical concepts in the treatment of periodontal or periimplantitis deficiencies with at crestal access flap to the periodontal or bony defect and debridement of the root or implant surface most often lead to partial defect regeneration and a soft tissue contraction and an increase in gingival recession [2, 3]. Even when the periodontal or periimplant parameters might be improved, the reduction of soft tissue volume is especially under esthetic aspect in the esthetic zone most often unacceptable.

An incision above the pathologic bony lesion is contrary to basic surgical treatment rules. Improved flap designs by means of a microsurgical approach led to reduction of periodontal trauma and a limited morbidity $[4,5]$, but still did not increase soft tissue esthetics.

The use of subepithelial connective tissue for grafting of sites with periodontal deficiencies and/or mucogingival recessions at the teeth is the gold standard procedure to provide significant root coverage, clinical attachment, and keratinized tissue gain ([6], Chambrone, [7-9]). This technique is used with coronal advanced flap procedure $[10,11]$ or tunnel technique [12]. The use of an additional connective tissue graft seems to improve the esthetic outcome significantly.

A new technique for the treatment of teeth with advanced periodontal support loss was recently described. They used an apical incision to access the periodontal defect and prevented thereby the marginal incision (non-incised papilla surgical approach (NIPSA)) for the periodontal regeneration procedure [13]. A modification of the NIPSA combined the apical incision with the incorporation of a connective tissue graft for periodontal regeneration and the support of a composite graft of deproteinized bovine bone xenograft (Bio-Oss, Geistlich) and an enamel matrix derivative (EMD, Emdogain, Straumann) [14]. The NIPSA enables better conditions for marginal healing and soft tissue support, and the early results show significant improvements in comparison to marginal incision techniques.

To overcome this problem, a new surgical concept was developed which allows to decontaminate and clean the implant surface, reconstruct the bony defect, and improve soft tissue height and thickness without cutting the papilla complex (Fig. 1). This technique was invented by the first author and received the name LAPIDER for laser-assisted periimplant defect regeneration.

This case documentation evaluates the 1-year outcome of an implant with severe periimplantitis treated with this modified approach for regenerative periimplantitis therapy.

\section{Material and methods \\ Patient}

A pilot case with a severe periimplant defect was treated in November 2018 to present this new surgical approach. This technique can be used in any location of the maxilla or mandible. In the presented case the periimplant lesion presented at an implant in the left posterior mandible. The Astra Tech Profile implant was inserted to replace the first molar in a narrow crest with buccal simultaneous bone grafting 2 years before. The female patient was healthy but was smoking between 10 and 20 cigarettes a day. She interrupted smoking just 1 week following implant surgery.

\section{Pre-treatment examination}

At pre-treatment examination, a periapical $\mathrm{x}$-ray was recorded to evaluate the marginal bone level at the implant site. The periimplant probing depths were between 8 and $10 \mathrm{~mm}$, the soft tissue recession was 4.5 $\mathrm{mm}$, and the width of the keratinized mucosa was 21.5 $\mathrm{mm}$. According to the classification of Schwarz [15], the 


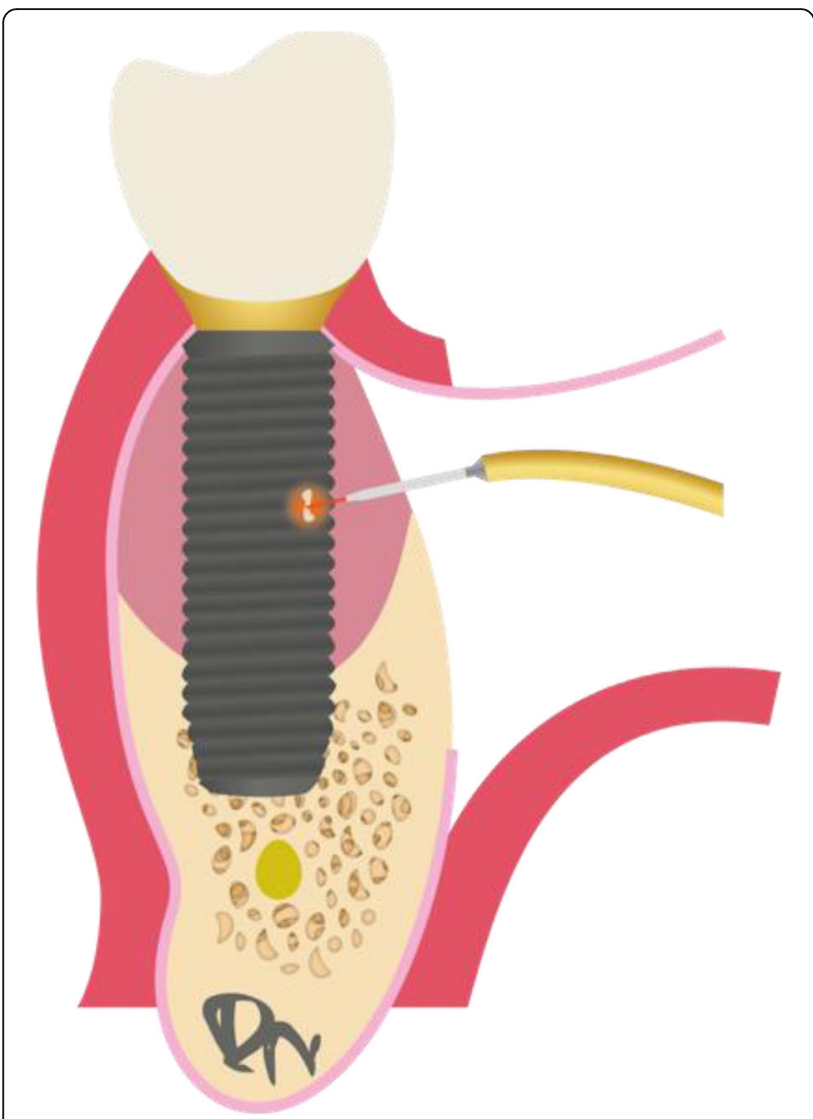

Fig. 1 Illustration of the LAPIDER treatment concept: a periimplantitis lesion around an implant with debris on the implant surface and circumferential bone loss and soft tissue recession is cleaned by the support of the Er:YAG laser

periimplantitis defect was classified as class Id. The bone loss was circumferential with a deep dehiscence bone loss on the buccal aspect. Bone loss was $9 \mathrm{~mm}$ at the buccal and $6 \mathrm{~mm}$ at the oral aspect apical to implant shoulder. The gingival biotype was determined as a thin tissue biotype [16].

\section{Surgical technique}

The implant was treated according to the LAPIDER treatment protocol: horizontal mucosal incision 4 to 5 $\mathrm{mm}$ apical to marginal mucosa, supraperiosteal split-flap preparation in apical direction (Fig. 2a), cutting through the periosteum at the level of the implant apex (Fig. 2b), subperiosteal coronal flap elevation, exploration and cleaning of the periimplant defect using a micro-surgical approach under a chair-side microscope (Fig. 2c), thorough debridement of the implant surface with the Er:YAG laser (AdvErL EVO, J. Morita Europe, Dietzenbach, Germany), and subperiosteal grafting with connective tissue (Fig. 2d). Simultaneous periimplant defect grafting was performed by condensing autogenous bone chips to the bottom of the defect for reconstruction of the periimplant defect (Fig. 2e). Autogenous bone grafts were harvested by a bone scraper (Micross, Meta, Reggio Emilia, Italy) at the mandibular ramus. The periosteum was reflected apically to cover the graft and sutured to the periosteum by a monofilamentous resorbable suture (Monocryl 5-0, Ethicon, Norderstedt, Germany). The bilayered suturing was finished with mucosal adaptation by a non-resorbable suture (Prolene 6-0, Ethicon, Norderstedt, Germany) (Fig. 2f).

The implant surface was irridated using the PS600 tip (J. Morita) on the Er:YAG laser. The flat quartz tip tapers from $600 \mu \mathrm{m}$ in the upper portion to $400 \mu \mathrm{m}$ in the lower portion. The distance from the end of the tip to the implant surface should be very close but without direct contact. Surface ablation was set to $50 \mathrm{~mJ} / \mathrm{mm}^{2}$, and the pulse was set to 20 pulses per second. Sterile water was injected at a rate of $5 \mathrm{ml} / \mathrm{min}$. Irridation time to clean the contaminated implant surface precisely was about $7 \mathrm{~min}$. Access to the lingual implant surface was provided by entering the defect through the lingual pocket with the slim laser tip under visual control from the buccal aspect.

\section{Follow-up and definition of outcome parameters}

The patient was examined preoperatively, at the time of periimplantitis surgery, at 3 and 6 months, and at 1-year following periimplantitis treatment (Fig. 2g).

\section{Interproximal marginal bone level}

The status of the interproximal marginal bone level was assessed using digital periapical radiographs (Fig. 2h).

\section{Buccal bone level and thickness}

The thickness of the facial bone wall was determined by CB-CT data, specifically by the reconstruction according to the long axis of the implant at follow-up examination (Fig. 2i). The thickness of the facial bone wall was measured $1 \mathrm{~mm}, 3 \mathrm{~mm}$, and $6 \mathrm{~mm}$ apical to the buccal implant shoulder level $[17,18]$.

\section{Probing depths}

The periimplant probing depths were measured at 6 sites around the implant by a periodontal probe with 1 mm calibration.

\section{Width of keratinized mucosa}

The width of the keratinized and attached mucosa at the midfacial aspect of the implant site was measured by a periodontal probe with $1 \mathrm{~mm}$ calibration.

\section{Soft tissue recession}

The midfacial soft tissue recession was calculated in relation to a tangent between the CEJs of the neighboring teeth. 


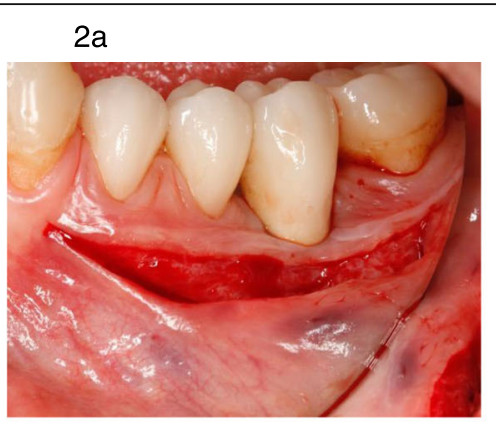

2c

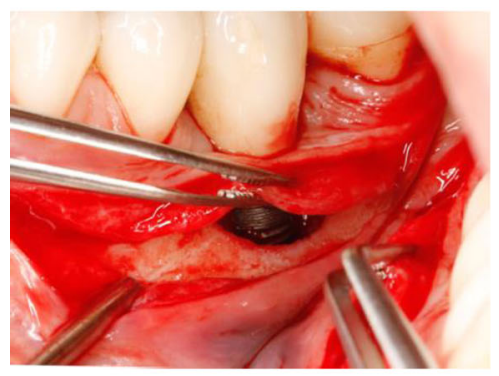

$2 e$

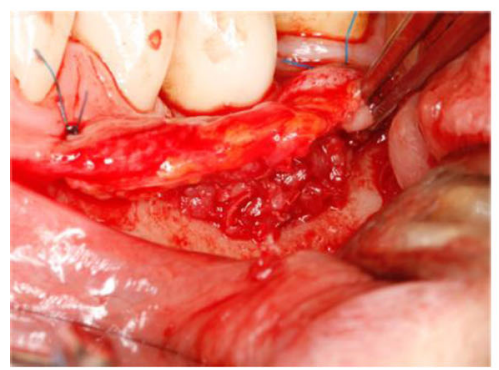

$2 g$
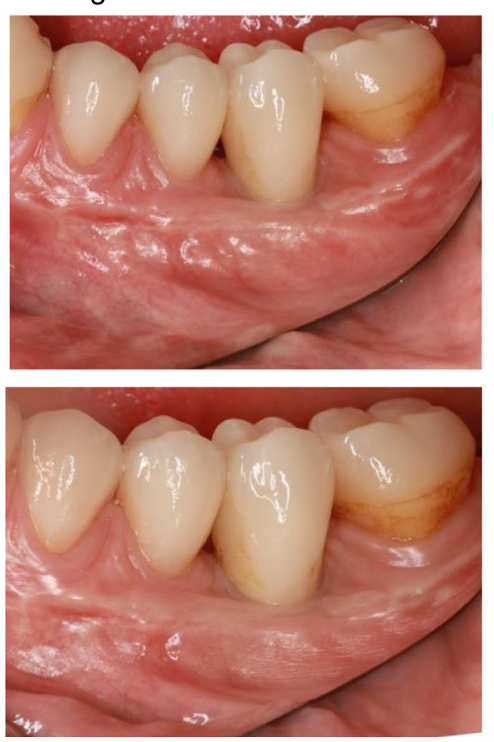

$2 b$

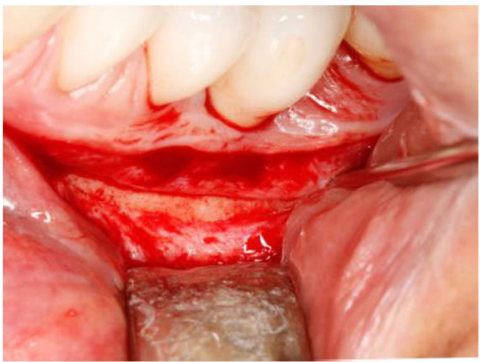

$2 d$

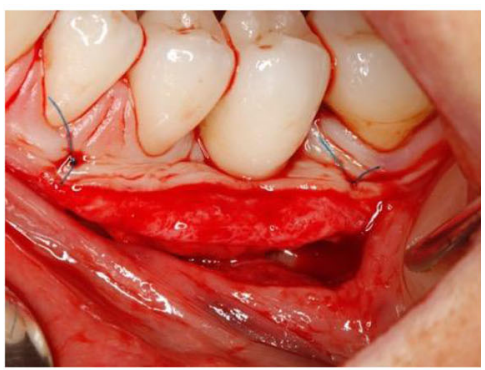

$2 f$

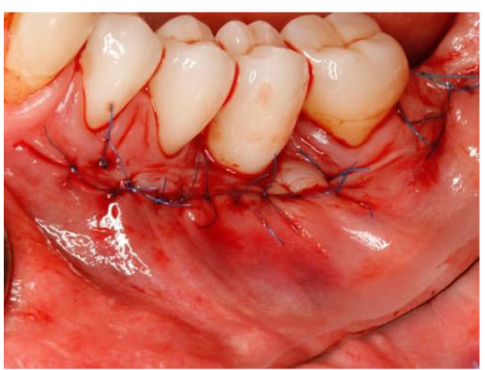

$2 \mathrm{~h}$

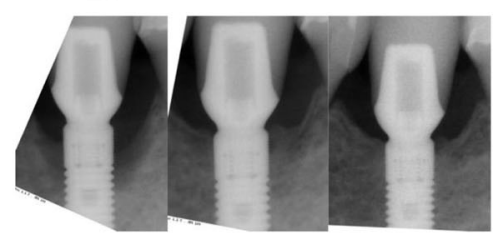

$2 i$

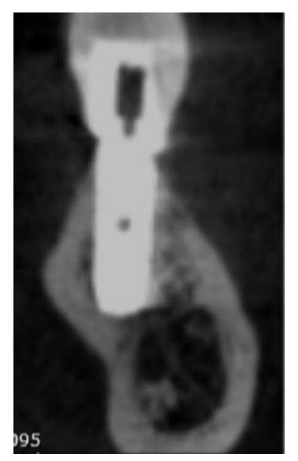

Fig. 2 (See legend on next page.) 


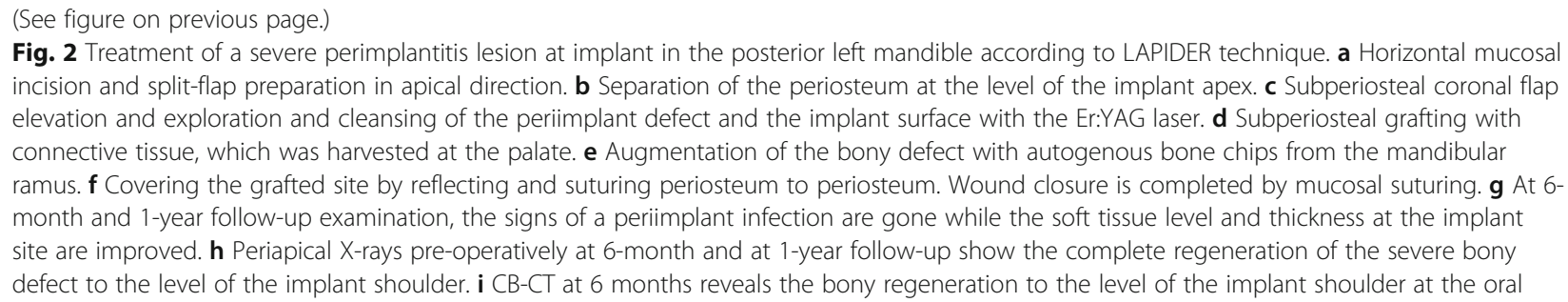

\section{Buccal mucosa thickness}

The facial mucosa thickness was measured using an ultrasonic device with $20 \mathrm{MHz}$ frequency and a $1540 \mathrm{~m} /$ $\mathrm{s}$ ultrasonic impulse velocity (PIROP Biometric Scanner; Echoson, Pulawy, Poland). The measurements were performed at a level $4 \mathrm{~mm}$ apical to the midfacial mucosal margin at the implant. Minimal pressure was applied to avoid compression of the mucosa.

\section{Results}

\section{Implant follow-up}

At 1-year follow-up, the implant was in function without any signs of infection.

\section{Interproximal marginal bone level}

The interproximal bone level changed from - $5.5 \mathrm{~mm}$ below to the level of the implant shoulder.

\section{Buccal bone level and thickness}

The buccal bone loss of $9 \mathrm{~mm}$ (measured clinically at periimplantitis surgery) regenerated to the level of the buccal implant shoulder (measured by CB-CT, Fig. 2i). The thickness of the buccal bone wall was $0.6 \mathrm{~mm}$ at 1 $\mathrm{mm}, 1.3 \mathrm{~mm}$ at $3 \mathrm{~mm}$, and $3.1 \mathrm{~mm}$ at $6 \mathrm{~mm}$.

\section{Probing depths}

The periimplant probing depths decreased from 8 to 10 $\mathrm{mm}$ to 2 to $3.5 \mathrm{~mm}$.

\section{Width of keratinized mucosa}

The width of the keratinized and attached mucosa at the midfacial aspect of the implant site improved from 1.5 to $3.5 \mathrm{~mm}$.

\section{Soft tissue recession}

The midfacial soft tissue recession decreased from 4.5 $\mathrm{mm}$ to $3 \mathrm{~mm}$.

\section{Buccal mucosa thickness}

The buccal mucosa thickness increased from $1.53 \mathrm{~mm}$ at pre-operative examination to $2.42 \mathrm{~mm}$ at 1-year follow-up.

\section{Discussion}

The role of keratinized tissues around implants is not finally elucidated, but seems to support periimplant health even it is not necessary in sites with perfect hygiene [19]. For the prevention of periimplantitis lesions, a systematic review [20] highlighted the clinical relevance of keratinized mucosa around dental implants in preventing periimplant disease. A sufficient width of keratinized mucosa led to less mucosal inflammation, less plaque accumulation, increased stability of the periimplant area, and prevention of mucosal recession.

The additional use of connective tissue grafts in the treatment procedure of periimplantitis lesions to improve the dimensions of the keratinized tissues is described in the literature as a beneficial additional method.

To improve the benefit on wound healing and flap stability with a coronally advanced flap for the treatment of gingival recessions, a clinical study observed the inclusion of periosteum in the flap versus a splitthickness approach showing that the inclusion of the periosteum led to a significant higher rate of complete root coverage [21].

In this study, it was possible to observe a significant increase in the width of the keratinized mucosa by grafting the sites with autogenous connective tissue grafts from the palate. This is supported by studies, which presented the impact of the regeneration of keratinized attached mucosa [22] and the advantage of autogenous soft tissue grafts in comparison to xenogeneic collagen matrices with a bilaminate structure especially in sites with an initially compromized width of keratinized mucosa smaller than $2 \mathrm{~mm}$ [23].

A retrospective study of our workgroup analyzed the relationship between hard and soft tissue thickness and several possible impacting factors like soft tissue grafting, implant angulation, and positioning at immediately provisionalized implants [24]. The statistical analysis showed no significant correlation between facial mucosa or bone thickness and the orofacial angulation and positioning of the implants. However, an increased thickness of the facial mucosa was observed in patients with a thick gingival morphotype and in cases with simultaneous connective tissue grafting. The amount of improvement of the thickness of the facial bony wall was 
dependent on the pre-operative deficiency. This implies, that a severe defect allows for a significant bigger amount of regeneration by immediate and flapless reconstruction with autogenous bone. This seems to be in line with the presented treatment protocol using autogenous bone and connective tissue grafts in severe periimplant defects. The data of the case report by Moreno Rodriguez et al. (Moreno Rodriguez, Ortiz Ruiz et al. 2019) show that an apical incision with Bio-Oss and EMD grafting combined with additional grafting of a connective tissue lead especially in compromised periodontal cases to an improvement in marginal tissues with reduction of pocket probing depths and gains in clinical attachment level.

The effectiveness of the cleansing procedure of the implant surface seems to have an important role on the capacity of bony regeneration around implants treated for periimplantitis. The methods of powder-abrasive therapy and the use of a Er:YAG laser seems to be the most effective procedures in non-surgical periimplantitis therapy [25]. A study using Er:YAG laser for periimplantitis treatment led to a significant reduction of probing depth and radiographically proven bone regeneration [26]. A new approach for surgical regenerative therapy of periimplantitis lesions using an electrolytic method to remove biofilms from contaminated implant surfaces was described by [27]). This technique requires the removal of the prosthetic restoration and the soft tissue coverage of the grafted site for a submerged healing. They showed that the electrolytic cleaning methods as a single procedure is effective and allows for significant clinical bone fill or complete re-osseointegration following covered defect grafting.

A present systematic review by Tomasi [28] aimed at evaluating the efficacy of reconstructive surgical therapy at periimplantitis-related bone defects. They reported a larger improvement in marginal bone levels and in defect fill for the test procedures compared to control procedures, but no differences for probing depth and bleeding on probing were found. Changes of clinical attachment and soft tissue levels were not considered. The available evidence on reconstructive therapy at periimplantitis-related defects is limited and the interpretation of the marginal bone level gain for test procedures is difficult as graft material may not be distinguishable from the newly formed bone.

The review of Madi et al. [29] considered possible surgical treatment modalities for periimplantitis defects to regain re-osseointegration. Various implant surface decontamination techniques have been used either alone or simultaneously with/without guided bone regeneration. Despite the access flap surgery, it was observed that the application of single decontamination measure either chemical or mechanical was not adequate to provide a better treatment outcome. Er: YAG laser showed no implant surface alteration and provided favorable environment for re-osseointegration.

The access to large periimplant defects at the lingual aspect is complicated and limits this technique. The slim laser tip allows to enter the bone defect and the implant surface through the lingual pocket. Simultaneous visual control from the buccal aspect is possible, but needs magnification and light. The waiver of a lingual incision is advantageous for bone regeneration by keeping the lingual tissue integrity and the maintenance of blood supply.

Even the initial results of this new approach for periimplantitis surgery are very promising, prospective studies are needed to examine the impact of this new approach of periimplantitis treatment strategy on hard and soft tissue regeneration.

\section{Conclusion}

Marginal bone levels and soft tissue results suggest feasibility for the regeneration of severe periimplant hard and soft tissue deficiencies by this new treatment approach. With the use of this concept, the simultaneous implant surface cleansing and improvement of hard and soft tissue seem to be possible and unfavorable postoperative exposition of titanium surface might be prevented. Adding a connective tissue graft simultaneously to periimplantitis treatment did increase the vestibular soft tissue thickness in short-term observation. As a next step, a comparative study has to identify the detailed and long-term results of the technique.

\section{Abbreviations \\ CB-CT: Cone beam computed tomography; NIPSA: Non-incised papilla surgical approach; EMD: Enamel matrix derivative (Emdogain)}

\section{Acknowledgements}

Not applicable.

Competing interests

The authors declare that they have no competing interests.

\section{Funding}

There was no funding for this publication or study.

\section{Availability of data and materials}

The dataset used and analyzed during the current publication is available from the corresponding author on a reasonable request.

\section{Authors' contributions}

RN was responsible for the surgical approach, the data analysis and interpretation, the data collection, and the writing of the paper. $\mathrm{BA}-\mathrm{N}$ was responsible for the data interpretation, the critical revision, and approval of the paper.

\section{Authors' information}

RN is a specialist for oral surgery, periodontics, micro-endodontics, and implant dentistry and is running a private practice limited to those topics in Lindau/Lake Constance, Germany. Additionally, he is working since 2005 as a senior physician and researcher at the University Medical Center in Mainz, Germany, in the Department for Oral and Maxillofacial Surgery with Professor 
Dr. Wilfried Wagner and since 2019 with Professor Dr. Bilal Al-Nawas. Since 1998 , he is working with microscopes on minimal-invasive protocols for esthetic implant dentistry. He is well known for the use of sloped implants supporting hard and soft tissues circumferentially in the esthetic zone. RN is a member of different professional organizations, author of several papers, and is lecturing frequently on national and international stages. He is running several studies for immediate insertion, restoration, and provisionalization protocols.

\section{Consent for publication}

The patient gave consent to publish her intraoral and radiographic images.

\section{Ethics approval and consent to participate}

The patient gave written informed consent after receiving a complete description of the periimplant surgical procedure.

Received: 16 February 2020 Accepted: 15 April 2020

Published online: 10 June 2020

\section{References}

1. Steven-Howe M, Richards D. Surgical regenerative treatment of periimplantitis. Evid Based Dent. 2017;18(3):79-81.

2. Farina R, Simonelli A, Minenna L, Rasperini G, Schincaglia GP, Tomasi C, Trombelli $L$. Change in the gingival margin profile after the single flap approach in periodontal intraosseous defects. J Periodontol. 2015:86(9): 1038-46.

3. Graziani F, Gennai S, Cei S, Cairo F, Baggiani A, Miccoli M, Gabriele M, Tonetti M. Clinical performance of access flap surgery in the treatment of the intrabony defect. A systematic review and meta-analysis of randomized clinical trials. J Clin Periodontol. 2012;39(2):145-56.

4. Cortellini $\mathrm{P}$, Tonetti MS. A minimally invasive surgical technique with an enamel matrix derivative in the regenerative treatment of intra-bony defects: a novel approach to limit morbidity. J Clin Periodontol. 2007;34(1): 87-93.

5. Cortellini P, Tonetti MS. Improved wound stability with a modified minimally invasive surgical technique in the regenerative treatment of isolated interdental intrabony defects. J Clin Periodontol. 2009;36(2):157-63.

6. McGuire MK, Nunn M. Evaluation of human recession defects treated with coronally advanced flaps and either enamel matrix derivative or connective tissue. Part 1: comparison of clinical parameters. J Periodontol. 2003;74(8): 1110-25.

7. Chambrone L, Chambrone D, Pustiglioni FE, Chambrone LA, Lima LA. Can subepithelial connective tissue grafts be considered the gold standard procedure in the treatment of Miller Class I and II recession-type defects? J Dent. 2008;36(9):659-71.

8. Trombelli L, Simonelli A, Minenna L, Rasperini G, Farina R. Effect of a Connective tissue graft in combination with a single flap approach in the regenerative treatment of intraosseous defects. J Periodontol. 2017;88(4): 348-56.

9. Zucchelli G, Mounssif I, Marzadori M, Mazzotti C, Felice P, Stefanini M. Connective tissue graft wall technique and enamel matrix derivative for the treatment of infrabony defects: case reports. Int J Periodontics Restorative Dent. 2017;37(5):673-81.

10. Cortellini P, Tonetti M, Baldi C, Francetti L, Rasperini G, Rotundo R, Nieri M Franceschi D, Labriola A, Prato GP. Does placement of a connective tissue graft improve the outcomes of coronally advanced flap for coverage of single gingival recessions in upper anterior teeth? A multi-centre, randomized, double-blind, clinical trial. J Clin Periodontol. 2009:36(1):68-79.

11. Langer $B$, Langer $L$. Subepithelial connective tissue graft technique for root coverage. J Periodontol. 1985:56(12):715-20.

12. Allen AL. Use of the supraperiosteal envelope in soft tissue grafting for root coverage. I. Rationaie and Tectinique. Int J Periodontics Restorative Dent. 1994:14:217-27.

13. Moreno Rodriguez JA, Caffesse RG. Nonincised Papillae Surgical Approach (NIPSA) in periodontal regeneration: preliminary results of a case series. Int J Periodontics Restorative Dent. 2018;38(Suppl):s105-11.

14. Moreno Rodriguez JA, Ortiz Ruiz AJ, Zamora GP, Pecci-Lloret M, Caffesse RG. Connective tissue grafts with nonincised papillae surgical approach for periodontal reconstruction in noncontained defects. Int J Periodontics Restorative Dent. 2019;39(6):781-7.
15. Schwarz F, Herten M, Sager M, Bieling K, Sculean A, Becker J. Comparison of naturally occurring and ligature-induced peri-implantitis bone defects in humans and dogs. Clin Oral Implants Res. 2007;18(2):161-70.

16. De Rouck T, Eghbali R, Collys K, De Bruyn H, Cosyn J. The gingival biotype revisited: transparency of the periodontal probe through the gingival margin as a method to discriminate thin from thick gingiva. J Clin Periodontol. 2009;36(5):428-33.

17. Buser D, Chappuis V, Bornstein MM, Wittneben JG, Frei M, Belser UC. Longterm stability of contour augmentation with early implant placement following single tooth extraction in the esthetic zone: a prospective, crosssectional study in 41 patients with a 5- to 9-year follow-up. J Periodontol. 2013;84(11):1517-27.

18. Januario AL, Duarte WR, Barriviera M, Mesti JC, Araujo MG, Lindhe J. Dimension of the facial bone wall in the anterior maxilla: a cone-beam computed tomography study. Clin Oral Implants Res. 2011.

19. Wennstrom $J$, Derks J. Is there a need for keratinized mucosa around implants to maintain health and tissue stability? Clin Oral Implants Res. 2010;23(Suppl 6):136-46

20. Pranskunas M, Poskevicius L, Juodzbalys G, Kubilius R, Jimbo R. Influence of peri-implant soft tissue condition and plaque accumulation on periimplantitis: a systematic review. J Oral Maxillofac Res. 2016;7(3):e2.

21. Clementini M, Discepoli N, Danesi C, de Sanctis M. Biologically guided flap stability: the role of flap thickness including periosteum retention on the performance of the coronally advanced flap-A double-blind randomized clinical trial. J Clin Periodontol. 2018;45(10):1238-46.

22. Karring $\mathrm{T}$, Lang NP, Loe $\mathrm{H}$. The role of gingival connective tissue in determining epithelial differentiation. J Periodontal Res. 1975;10(1):1-11.

23. Monteiro H, Peruzzo D, Martines E, Napimoga M, Boulinari A, Joly J. Periimplant soft tissue augmentation with palate subepitelial connective tissue graft compared to porcine collagen matrix: a randomized controlled clinical study and histomorphometric analysis. International Journal of Applied Dental Sciences. 2019;5(3):319-25.

24. Noelken R, Geier J, Kunkel M, Jepsen S, Wagner W. Influence of soft tissue grafting, orofacial implant position, and angulation on facial hard and soft tissue thickness at immediately inserted and provisionalized implants in the anterior maxilla. Clin Implant Dent Relat Res. 2018;20(5):674-82.

25. Muthukuru M, Zainvi A, Esplugues EO, Flemmig TF. Non-surgical therapy for the management of peri-implantitis: a systematic review. Clinical Oral Implants Research. 2012;23(Suppl 6):77-83.

26. Clem D, Gunsolley JC. Peri-implantitis Treatment Using Er:YAG laser and bone grafting. a prospective consecutive case series evaluation: 1 year posttherapy. Int J Periodontics Restorative Dent. 2019;39(4):479-89.

27. Schlee M, Rathe F, Brodbeck U, Ratka C, Weigl P, Zipprich H. Treatment of peri-implantitis-electrolytic cleaning versus mechanical and electrolytic cleaning-a randomized controlled clinical trial-six-month results. J Clin Med. 2019;8(11).

28. Tomasi C, Regidor E, Ortiz-Vigon A, Derks J. Efficacy of reconstructive surgical therapy at peri-implantitis-related bone defects. A systematic review and meta-analysis. J Clin Periodontol. 2019;46(Suppl 21):340-56.

29. Madi M, Htet M, Zakaria O, Alagl A, Kasugai S. Re-osseointegration of dental implants after periimplantitis treatments: a systematic review. Implant Dent. 2018;27(1):101-10

\section{Publisher's Note}

Springer Nature remains neutral with regard to jurisdictional claims in published maps and institutional affiliations. 